\title{
Do Political Attitudes Matter for Epistemic Decisions of Scientists?
}

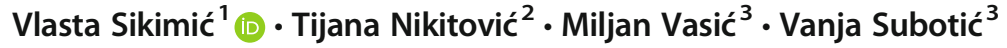

Published online: 25 August 2020

(C) The Author(s) 2020

\begin{abstract}
The epistemic attitudes of scientists, such as epistemic tolerance and authoritarianism, play important roles in the discourse about rivaling theories. Epistemic tolerance stands for the mental attitude of an epistemic agent, e.g., a scientist, who is open to opposing views, while epistemic authoritarianism represents the tendency to uncritically accept views of authorities. Another relevant epistemic factor when it comes to the epistemic decisions of scientists is the skepticism towards the scientific method. However, the question is whether these epistemic attitudes are influenced by their sociopolitical counterparts, such as the researcher's degree of conservatism. To empirically investigate the interplay between epistemic and sociopolitical attitudes of scientists, we conducted a survey with researchers $(N=655)$ across different disciplines. We propose scales for measuring epistemic tolerance and epistemic authoritarianism, as well as a scale for detecting the participants' readiness to question the scientific method. Furthermore, we investigate the relationship between epistemic tolerance and epistemic authoritarianism on the one hand, and career stage and sociopolitical views on the other hand. Interestingly, our study found only small correlations between the participants' degree of conservatism and their epistemic attitudes. This suggests that political views, against common argumentation, actually do not play an important role in one's scientific decisions. Moreover, social scientists scored higher on the epistemic tolerance and lower on the epistemic authoritarianism scale than natural scientists. Finally, the results indicate that natural scientists question the scientific method less than social scientists.
\end{abstract}

Vlasta Sikimić

vlasta.sikimic@uni-tuebingen.de

1 Carl Friedrich von Weizsäcker Center, University of Tübingen, Tübingen, Germany

2 Institute of Psychology, Department of Psychology, Faculty of Philosophy, University of Belgrade, Belgrade, Serbia

3 Institute for Philosophy, Department of Philosophy, Faculty of Philosophy, University of Belgrade, Belgrade, Serbia 


\section{Introduction}

Scientists, in addition to their methodological stances, hold a whole array of sociopolitical views. Moreover, scientists develop epistemic attitudes that resemble political ones. For instance, they can be more or less epistemically tolerant towards opposing scientific theories or follow leading authorities in their disciplines with different levels of trust. The legitimate question arises whether non-epistemic attitudes of scientists, such as moral values, reflect on their epistemic attitudes and general beliefs about science. In other words, one could argue that non-epistemic values influence the scientists' views on the relationship between a scientific hypothesis and the evidence, or their perception of the scientific method (cf. Colombo et al. 2016).

The debate about the interplay between sociopolitical and epistemic values of scientists can be traced to classical contributions in the history of philosophy of science. For instance, Karl Popper urged scientists to remain epistemically open since "only if criticism meets resistance can we learn the full force of a critical argument" (Popper 1994: 92). There is a connection between Popper's epistemic and sociopolitical views. Popper's idea of piecemeal social engineering (e.g., 1945a: 139, 1957: 66-67) - a gradual improvement of public policies through trial and error - can be traced to his view that scientific theories are fallible, i.e., that they can be falsified and abandoned. Moreover, Popper (1945a, b) argued that this can only be achieved in a society that is open to critical discussions and acts upon them in the same way in which scientists should be epistemically open for critical arguments. The self-declared epistemological anarchist about methodological rules Paul Feyerabend (1975/1993) defended an open and critical attitude towards the scientific method arguing in favor of competing methods and values in science and criticizing the blind trust in epistemic authority. For Feyerabend, his epistemic and methodological attitudes were closely connected to his sociopolitical views. For example, according to Martin (2019), Feyerabend was inclined to argue that only theoretical pluralism, including pseudoscientific endeavors, can oppose the "stifling conformism" of contemporary science and epistemology after he had read Mill's On Liberty. Furthermore, Martin (2019) claims that Feyerabend's concerns were how to allow for the views of the minority to exist in science and how to control, so-to-say, the epistemic tyranny of majority beliefs.

Some notable recent contributions defend a pluralist scientific method and an open epistemic attitude in science. Straßer et al. (2015) introduced the concept of epistemic tolerance in the context of scientific disagreement, which is in line with authors who enlist epistemic tolerance as an epistemic virtue allowing for a diversity of methods and promoting scientific progress (e.g., Chang 2012; Longino 2002). Moreover, probability models and case studies from history of science support the exploration of less likely hypotheses as epistemically beneficial for the scientific community (Kitcher 1990, 1993). Kitcher (1990) argues that the optimal distribution of cognitive labor requires the investigation of diverse and opposing theories with the underlying assumption that the exploration of these views has a scientific value. Similarly, Strevens (2003) showed epistemic advantages of exploring diverse hypotheses using formal modeling. Finally, Zollman's formal results show the importance of cognitive diversity for the accuracy of the scientific consensus and emphasize the need for openness towards rivaling theories from the perspective of the scientific community as a whole (Zollman 2007, 2010). 
Epistemic authoritarianism is explored in the field of political philosophy and represents the tendency to accept the epistemic authority in the normative field (e.g., Estlund 1992). In the context of the scientific community, epistemic authoritarianism is linked to the rigid acceptance of dominant scientific paradigms and approaches in a specific field and leading authorities that dictate them. Once an epistemically authoritarian scientist adopts prevailing beliefs, her tendency to question or revise them will be limited. Such authoritarianism is the basis for other epistemic vices, such as epistemic conformity, intellectual dogmatism, closed-mindedness, or learning myopia (cf. Battaly 2014). Epistemic tolerance and epistemic authoritarianism directly influence the researchers' decisions about rivaling theories in their field. Epistemically tolerant scientists will not instantly dismiss opposing views, bold hypotheses, and novel approaches. Researchers who are skeptical about the general inductive method of science will also take into account the limitations of science. These notions can also be understood in the light of Thomas Kuhn's philosophy of science. On the one hand, Kuhn (1977c; 1977/2000) acknowledged the importance of the rational disagreement of researchers when it comes to choosing a scientific theory. On the other hand, Kuhn (1977a, b, c) noticed how the interpretation of data and the evaluation of hypotheses critically depend on scientists' convergence on a common set of assumptions during the periods of normal science, i.e., periods when scientists work within one paradigm. Shared values, shared assumptions and following established research paths - in short, moving within a scientific paradigm - are indispensable for scientists' daily work. Kuhn (e.g., Kuhn 1962/1970: 1, 137, Kuhn 1977a) also critically explained that textbooks during normal science mainly present the dominant views and sometimes even rewrite the history in favor of dominant paradigms. These textbooks influence the education and formation of junior researchers and make them less critical of dominant views (e.g., Kuhn 1962/1970: 5, 167).

The question of how one's sociopolitical views, such as the level of conservatism, could influence one's epistemic stances was also raised from the perspective of social psychology. It has been argued that the underlying basis of conservatism is both cognitive and motivational (Jost et al. 2003). As such, it can be found in one's desire to arrive at a firm belief or understanding on a given topic, as opposed to uncertainty. In this sense, epistemic motives (i.e., intolerance of ambiguity, closed-mindedness, uncertainty avoidance, need for order, structure, and closure) are assumed to govern how people acquire beliefs, whether on sociopolitical or scientific topics (Jost et al. 2003). Thus, we were interested in finding out whether epistemic motives such as epistemic tolerance and authoritarianism are related to sociopolitical views as well.

More recently, Rutjens et al. (2018) showed that beliefs about science and pseudoscience depend, among other things, such as religiosity and moral convictions, on political conservatism. However, one could object that, though these findings are relevant when analyzing laypersons' evaluation of scientific output, scientists can be regarded as epistemically privileged. Therefore, one could expect that the epistemic attitudes they obtain after years of training are superior and less sullied by their political views, than the epistemic attitudes of their students who have just started the scientific learning process. Indeed, much of the traditional philosophy of science (cf. Kuhn 1977c) emphasizes the difference between epistemic and non-epistemic values, i.e., the very assessment of scientific hypotheses and data should be based on values pertaining to the pursuit of truth rather than political or economic values. However, 
in the contemporary literature a different accent is placed on the discussion about the role of non-epistemic values in science (e.g., Douglas 2000, 2009; Elliott 2011). According to Douglas (2000, 2009), non-epistemic values play an indirect role by providing scientists with the means to decide what counts as sufficient evidence, whereas the direct role of the values of scientists amounts to finding reasons why a theory should be adopted. Douglas argues that the inductive risk is present not only at the "external" stage of theory acceptance but also at the "internal" stages of methodology choice, data gathering, and data interpretation (cf. 2000: 566-577). She offers a new image of the scientist, now portrayed as an active and responsible agent whose reasoning should never be detached from ethical and social influences.

Straßer et al. (2015:113) remarked that the literature in social epistemology "lacks a proper account of the epistemically appropriate response scientists should have towards opposing positions in peer disagreements." On the contrary, we think that the first step towards such an account is an inquiry into the epistemic responses scientists do have towards opposing positions in their field and towards the scientific method in general. Accordingly, our research goal was to empirically investigate the interplay between epistemic attitudes, i.e., epistemic tolerance, epistemic authoritarianism, and skepticism about the scientific method (Fig. 1). The sociopolitical attitudes that we measured independently were the participants' level of conservatism and their political orientation. Finally, we investigated the beliefs that researchers have about science and pseudoscience. In particular, we were interested in their degrees of belief in astrology and their tendency to question the theory of evolution.

\subsection{Research Aims and Hypotheses}

Since the epistemic attitudes that we were interested in, i.e., epistemic tolerance, epistemic authoritarianism, and skepticism towards the scientific method, have not been empirically measured before, one of our main research aims was to reasonably well operationalize these philosophical notions by proposing scales for measuring them. Given the theoretical background of these notions, we expected them to be distinct but related to the non-epistemic attitudes and beliefs that we tested (Fig. 1). Thus, the nature of our pioneering study was exploratory.

In order to construct and test our hypotheses clearly and unambiguously, we have provided quantitative effect size predictions in the form of the smallest effect size of

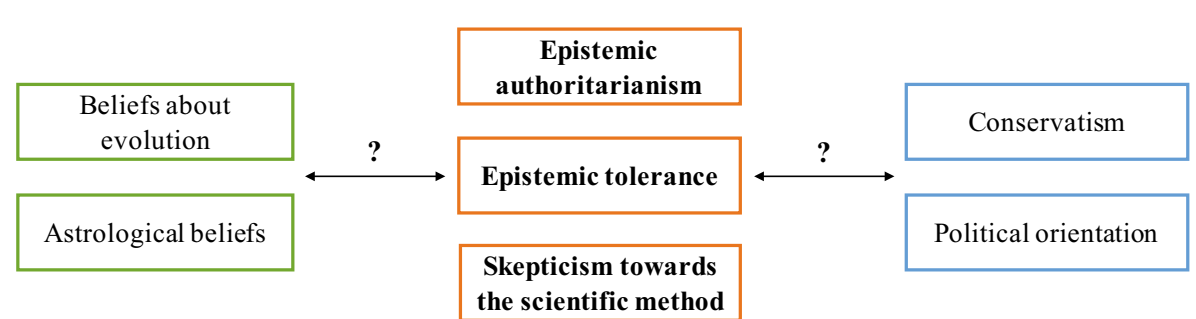

Fig. 1 An overview of the main theoretical concepts. Note. Bold font stands for the central attitudes of interest 
significance for each hypothesis. The quantification of the hypotheses faced several challenges. One obstacle lies in the nature of the measures used in this research. Namely, the measures of the constructs are in the form of 5-point Likert scales, meaning that there is a problem in translating the quantitative differences into something meaningful in the real-world (Anvari and Lakens 2019). This is even more challenging because there is a limited amount of research on similar topics and no meta-analyses that could be used as guidelines for determining the expected effect sizes. Nonetheless, we have provided theoretical motivation for our hypotheses, as well as quantitative effect size predictions. These predictions were, when possible, based on results from past research on related constructs and several expected effect sizes were based on general statistical recommendations as no similar studies have been conducted thus far. Expected effect sizes were specified in the form of calculated indices of effect size (i.e., Cohen $d$ ) rather than absolute effect sizes as these measurements (i.e., Likert scales) have no intrinsic meaning (Sullivan and Feinn 2012). We have taken the recommended effect size of Cohen $d=.4$ as a reference point, as this is the average effect size in psychology (Brysbaert 2019), with values greater than $d=.5$ indicating moderate effect size (Cohen 1988). We have also calculated the power of the tests used to assess our hypotheses with the $\mathrm{G}^{*}$ Power software. The motivation behind this lies in the fact that many studies in the field of behavioral sciences are underpowered (Sedlmeier and Gigerenzer 1989; Ioannidis 2005; Open Science Collaboration 2015).

As the first hypothesis, we wanted to trace a possible relationship between conservatism and epistemic attitudes. Since an overview of the psychological literature showed that epistemic motives are significantly related to social conservatism (Jost et al. 2003), it was possible that these epistemic motives also partially constitute epistemic authoritarianism and epistemic tolerance. We estimated the correlation size based on a negative correlation of $r=-.11$ between intellectual humility in the sociopolitical domain and conservatism (Krumrei-Mancuso \& Newman 2020). These coefficients correspond with Cohen's (1988) definition of a small effect, that could be expected in this type of study design, i.e., a non-experimental exploratory study that operationalized novel constructs. Thus, explicitly stated, we postulated the following hypotheses.

Hypothesis 1a. The correlation between epistemic authoritarianism and conservatism will be positive, and at least be of the size Pearson's $r=.10$.

Hypothesis 1b. The correlation between epistemic tolerance and conservatism will be negative, and at least be of the size Pearson's $r=-.10$.

Secondly, our study aimed at investigating whether skepticism towards the scientific method is more typical for right-wing researchers, or perhaps both ends of the political spectrum show certain similarities. For this reason, we proposed two competing hypotheses. The first hypothesis postulates that right-wing researchers will be more skeptical towards the scientific method. This hypothesis was made having in mind related research showing that rightists have a tendency of questioning some important scientific claims such as climate change (e.g., Dunlap and McCright 2008) or the safety of vaccines (e.g., Hamilton et al. 2015). On the other hand, in line with Feyerabend's argumentation against a unique scientific method that is related to his left political ideas (cf. Martin 2019), the second hypothesis states that leftists would also express skepticism towards the scientific 
method. However, this skepticism would reflect their tendency to question the currently established scientific practices, but not the scientific endeavor en général, while rightists would show skepticism towards scientific methods and results altogether. Formally expressed, we assumed the following.

Hypothesis 2a. There will be at an effect of political orientation, with right-wing researchers being more skeptical towards the scientific method than left-wing researchers, with the effect size of at least of $d=.4$.

Hypothesis 2b. There will be no difference between left and right-wing researchers on the value of skepticism towards the scientific method, with both groups scoring higher than $M=3$, i.e., the neutral point on the Likert scale.

As for the participant's scientific field, we assumed that researchers working in natural sciences would tend to doubt the scientific method less and to be more epistemically authoritarian than those working in social sciences because of the nature of their methodologies. Besides obvious differences, viz. that natural scientists work in technologically equipped and highly specialized laboratories, and that most of the social scientists, especially those working in the humanities (e.g., philosophy, history, ethnology, linguistics, philology, etc.) are using rather different methods (conceptual analysis, historical method, synoptic method, discourse analysis, etc.), one can also trace differences in the way of conducting and publishing original research. According to Kuhn's (1962/1970) famous discussion about paradigmatic and pre-paradigmatic science, there is a difference between sciences that already have a developed paradigm under which their research is conducted, while in the pre-paradigmatic state a plurality of competing approaches exists alongside each other. Big developments like Darwin's theory shift a science from the pre-paradigmatic to the paradigmatic stage (Kuhn 1962/ 1970). According to this theory, humanities and social science are still in the preparadigmatic stage. Following Kuhn, one can expect differences in responses between natural and social scientists on the epistemic tolerance, epistemic authoritarianism, and skepticism towards the scientific scales.

Moreover, Jaffe (2014) offered a quantitative analysis of bibliometric data of scientific publications thereby accounting for different research strategies in natural and social sciences. Thus, Jaffe brought to light that natural scientists adhere to a "follower" strategy resulting in publications with multiple authors, a high level of international collaboration, as well as a high citation rate from the colleagues publishing in the same target journals; whereas social scientists seem to care more about originality than following in the footsteps of already tackled topics, so they end up with publications characterized by high levels of self-citations, a low citation rate in a wide range of journals and a low level of international collaboration. Jaffe's results are in line with bibliometric trends already reported in papers tracing the coauthorship patterns such as Frame and Carpenter (1979), Luukkonen (1992), and Persson et al. (2004), as well as more recently in Parish et al. (2018). These studies also indicate that greater international research collaboration has been observed to coincide with elevated citation impact and to represent a vital characteristic of the "hard science", most notably physics, medicine, and biology. To sum up, when it comes to the relationship between the scientific field and the epistemic attitudes, we postulated the following. 
Hypothesis 3a. There will be at least an effect of $d=.4$ of the scientific field on the value of the epistemic authoritarianism scale, with researchers from natural sciences scoring higher than the ones from social sciences.

Hypothesis 3b. There will be at least an effect of $d=.4$ of the scientific field on the value of epistemic tolerance, with researchers from social sciences scoring higher than the ones from natural sciences.

Hypothesis 3c. There will be at least an effect of $d=.4$ of the scientific field on the value of skepticism towards the scientific method, with researchers from social sciences scoring higher than the ones in natural sciences.

Also, we postulated the career stage of researchers as relevant for their epistemic attitudes and assumed that senior researchers would be less skeptical about the scientific method than junior ones since they have received more training, their professional experience is more enriched with age, and their theoretical views are refined. Closely related to this, is the assumption concerning the degree of epistemic tolerance of junior researchers. Given their young age and susceptibility to various theoretical influences, we expected that they would be less dogmatic and more inclined to reassess dominant paradigms in their disciplines. Moreover, we assumed that epistemic authoritarianism is related to the time spent researching in a specific science field following its dominant paradigms. Thus, we started from the following two assumptions.

Hypothesis 4a. There will be at least an effect of $d=.4$ of career stage on the value of epistemic authoritarianism with senior researchers being more authoritarian than junior researchers.

Hypothesis $4 \mathbf{b}$. There will be at least an effect of $d=.4$ of career stage on the value of skepticism towards the scientific method, with senior researchers being less skeptical than junior researchers.

Lastly, we set out to examine the difference between senior and junior researchers concerning their stances towards pseudoscience in general. Research in social psychology explored inclinations of laymen to believe in pseudoscientific statements and question science (e.g., Rutjens et al. 2018). We wanted to explore whether there is a difference in the degree of belief in pseudoscientific claims between senior and junior researchers, assuming that more experienced researchers will question science less. Thus, we postulated the following hypotheses about the beliefs in science.

Hypothesis 5a. There will be at least an effect of $d=.4$ of career stage on astrological beliefs, with junior researchers holding higher beliefs than senior researchers.

Hypothesis 5b. There will be at least an effect of $d=.4$ of career stage on beliefs about evolution, with junior researchers questioning evolution more than seniors.

In order to test these hypotheses, we conducted an online survey and explored the interplay between the epistemic and the political attitudes of scientists. We propose scales for measuring the level of their 1) epistemic tolerance, 2) epistemic authoritarianism, and 3) skepticism towards the scientific method. Moreover, to investigate the relationship between epistemic attitudes and sociopolitical views, we asked scientists to position 
themselves on the political spectrum and included a separate scale for measuring the level of their conservatism. Finally, in order to better assess participants' general tendency to relativize science, we included measures of their beliefs in science and pseudoscience.

\section{Method}

\subsection{Participants}

The study was conducted among 655 participants from Serbia ${ }^{1}$ (248 male, 352 female, and 55 genders not reported), 18 to 74 years old $(M=29 ; S d=11)$ through purposive and convenience sampling methods. Participants reported their education level, as well as their field of study. Based on these data, the participants were classified as either junior $(75.4 \%$, from undergraduate studies to Ph.D. studies) or senior researchers (24.6\%, with a doctorate degree). Participants specified their scientific discipline, based on which we categorized them in either the field of natural or social sciences (Appendix Tables 6 and 7). This was done because of a small proportion of some disciplines in the overall sample, as well as a disproportion of junior and senior researchers in certain disciplines. For this reason, further analyses were conducted with two categories, the field of natural (48.9\% of participants) or social (51.1\%) sciences. The rather large scale of the sample was necessary in order to gather a sufficient number of participants from different categories, i.e., junior and senior researchers from different fields, as well as participants with different political orientations, since we wanted to analyze differences between these categories. Besides a scale measuring economic and social conservatism, an ideological measure included in the study is the participants' self-report of their political orientation. We initially used a seven-point scale ( -3 as an indication of far left, -2 left, -1 moderately left, 0 center, 1 moderately right, 2 right, 3 far right). However, because a small number of participants reported being on the right side of the spectrum, categories were narrowed down to three: left $(64.2 \%)$, center $(23 \%)$, and right $(12.8 \%)$. Further analyses were conducted on these three categories.

\subsection{Item Development}

Given the lack of empirical research on epistemic attitudes, this aspect of the present study is exploratory. One of our aims was to operationalize epistemic authoritarianism and tolerance, as well as skepticism towards the scientific method. These instruments represent multidimensional measures of epistemic attitudes, as modeled on an overview of the literature of previous attempts to measure a related construct, i.e., views on the nature of science (Deng et al. 2011).

Epistemic attitudes operationalized within two scientific field-dependent dimensions are epistemic tolerance and authoritarianism. Epistemic tolerance is operationalized using seven items that indicate the awareness of scientists that the views of researchers with opposing approaches might have scientific value (e.g., The opinions of the researchers I disagree with should be taken into consideration; Even the papers of

\footnotetext{
${ }^{1}$ Serbia is a good choice for a study that includes sociopolitical values, as the country in its recent history experienced both extensively left and right political systems.
} 
the researchers I disagree with are scientifically valuable). The items are constructed to measure the epistemic tolerance within the researchers' specific field of expertise in the situations of rational disagreements between peers. The epistemic authoritarianism scale also consists of 7 items that were formulated to indicate researchers' firm acceptance of dominant paradigms, approaches or theories in their discipline, as well as their reluctance to question these prevailing views (e.g., The academic authorities in my field are right; Some of the results within my scientific field are conclusively proved and should not be questioned). Participants indicated their attitudes on a 5-point Likerttype scale, ranging from strong disagreement to strong agreement with the constructed statements (i.e., 1 = strongly disagree, 2= mostly disagree, $3=$ neither agree nor disagree, $4=$ mostly agree, $5=$ strongly agree). All items can be found in Appendix 2.

The scale measuring skepticism towards the scientific method is inspired by the philosophical considerations that were discussed in section 1 . The content of the scale does not restrict itself to the participants' field of study; rather, it is about attitudes towards science in general, as well as specific fields, such as mathematics. ${ }^{2}$ By including items concerning the status of mathematics, this scale is designed to measure radical relativism alongside skepticism towards methods of both natural and social sciences. The skepticism towards the scientific method was assessed in three domains: a) scientists' subjectivity (4 items, example: What scientists publish is more a reflection of their opinion, than the objective truth), b) stochastic progress of science (3 items, example: Progress in science is achieved solely by mere chance) and c) intelligibility of the objective truth (5 items, example: Science will never be able to adequately describe reality). We made this decision in part due to an overview of previous research on a related phenomenon (i.e., views on the nature of science), which was treated as a multidimensional construct (Deng et al. 2011). Participants indicated their attitudes towards statements about an aspect of skepticism on a 5-point Likert-type scale, which ranged from strong disagreement to strong agreement. For all items, a skeptical position was reflected by a high score. All items are listed in Appendix 2.

\subsection{Procedure}

Participants were directed to a set of online questionnaires on the Limesurvey platform. ${ }^{3}$ After participants gave their informed consent, they were presented with instructions (see Appendix 2), followed by the questionnaires. The order of presentations of scales was fixed, while the order of items within the scales was randomized. The first questionnaire was a measure of skepticism towards the scientific method. This measure was constructed by the researchers and assessed beliefs about skepticism towards the scientific method (SSM scale) in three domains. The items from the epistemic tolerance and authoritarianism scales were then presented together and in a randomized order. These measures consist of 7 items each and assess epistemic authoritarianism and tolerance towards theories and researchers in one's scientific discipline. Participants also completed two 5-point scales that indicated their attitudes towards science and pseudoscience. One scale assessed participants' beliefs about the theory of evolution and

\footnotetext{
${ }^{2}$ Both items measuring views on mathematics are part of the subscale intelligibility of the objective truth. An example of an item is "Laws of mathematics will be revised in the future as well."

${ }^{3}$ Limesuvery is a professional online survey platform: https://www.limesurvey.org.
} 
it is an adaptation of an existing scale (Johnson and Peeples 1987). The other is an adaptation of Randall and Desrosiers' (1980) scale concerning attitudes towards astrology. Participants' sociopolitical views were measured with Everett's (2013) 12-item Social and Economic Conservatism Scale (SECS) that was adapted for our study. Participants were given words or phrases and asked to rate them on a 'feeling thermometer' where 10 represents very negative, and 100 represents very positive feelings about an issue. In addition to translating the scale, we excluded two items concerning gun control and immigration policies, as these topics are more suitable indicators of conservatism in the USA than in Serbia. Lastly, participants were asked to provide demographic information (i.e., field of study, education level, political orientation).

\section{Results}

We will first present descriptive statistics and measures of reliability and representativeness for the scales we constructed. A confirmatory factor analysis was also conducted in order to test the construct validity of our scales. Further results are presented in the same order as the hypotheses are proposed. The first hypothesis is tested by calculating the Pearson correlation coefficient that was used for assessing the relationships between the other constructs as well. Additionally, we have conducted a principal component analysis in an attempt to transform the study variables into a smaller number of underlying constructs. In order to investigate group differences among our participants (hypotheses 2-5), we performed analyses of variance (ANOVAs).

\subsection{Descriptive Measures and Psychometric Properties of Epistemic Attitudes}

Descriptive statistics for the scales measuring epistemic attitudes appear in Table 1. Our results show that researchers are generally epistemically tolerant, and are not epistemically authoritarian or skeptical towards the scientific method. This is further seen in values of skewness and kurtosis, as well as from Kolmogorov-Smirnov tests of normality that indicate that the relevant variables are normally distributed. The internal reliability, represented by the symbol $\alpha$ in Table 1, for the scales for epistemic tolerance and epistemic authoritarianism is acceptable (Nunnally and Bernstein 1994). The skepticism towards the scientific method scale is divided into the subscale scores of scientists' subjectivity, stochastic progress of science, and the intelligibility of the objective truth. Both the subscores and full-scale scores are presented. The scale as a whole has acceptable internal reliability. ${ }^{4}$ The KaiserMeyer-Olkin (KMO) measure of representativeness was calculated in order to assess the proportion of common variance between variables in a particular scale. All measures of KMO are above 0.8, indicating adequate sampling (Kaiser and Rice 1974) for all scales (Epistemic tolerance: $\mathrm{KMO}=.81, \chi^{2}(21)=781.50, p<.001$; Epistemic authoritarianism: $\mathrm{KMO}=.83, \chi^{2}(21)=747.81, p<.001$; Skepticism towards the scientific method: $\left.\mathrm{KMO}=.88, \chi^{2}(21)=2179.90, p<.001\right)$.

\footnotetext{
${ }^{4}$ On the other hand, subscales' reliability ranges from poor $(\alpha=.53)$ to acceptable $(\alpha=.77)$. This is to be expected given the small number of items per scale and indicates that for further analyses this scale should be used as a whole.
} 
Table 1 Descriptive statistics and psychometric properties of epistemic attitudes

\begin{tabular}{llllrrr}
\hline Measure & M & SD & Minimum-Maximum & Std. Sk & Std. Ku & $\alpha$ \\
\hline Epistemic tolerance & 4.4 & 0.5 & $1.7-5.0$ & -12.78 & 11.37 & .75 \\
Epistemic authoritarianism & 2.5 & 0.7 & $1.0-4.9$ & 3.41 & 0.66 & .74 \\
Skepticism towards the scientific method & 2.2 & 0.6 & $1.0-4.2$ & 6.14 & -0.01 & .82 \\
Scientists' subjectivity & 2.4 & 0.8 & $1.0-4.7$ & 4.84 & -0.74 & .77 \\
Stochastic progress of science & 1.9 & 0.6 & $1.0-4.0$ & 9.50 & 5.10 & .53 \\
Intelligibility of the objective truth & 2.3 & 0.8 & $1.0-4.6$ & 5.09 & -1.97 & .68 \\
\hline
\end{tabular}

M stands for mean, SD for standard deviation, Std. Sk for standardized skewness, Std. Ku for standardized kurtosis and $\alpha$ for Cronbach $\alpha$. Theoretical minimum and maximum of the scales range from 1 to 5

\subsection{Construct Validity of Epistemic Attitudes Scales}

In order to assess the construct validity of our scales in this phase, we have conducted confirmatory factor analysis. This analysis included items from three scales measuring epistemic attitudes, i.e., epistemic authoritarianism, epistemic tolerance, and skepticism towards the scientific method. The Kaiser-Meyer-Olkin measure of sampling adequacy and Bartlett's test of sphericity indicated that the data are suitable for factor analysis, $\mathrm{KMO}=.871, \chi^{2}(325)=4339.32, p<.001$. A maximum-likelihood confirmatory factor analysis was conducted with the number of factors fixed to three and the promax rotation. The model explains $32 \%$ of the variance.

The pattern matrix for the 3 -factor solution is shown in Appendix 3 (Table 8). The first factor includes items from the scale measuring skepticism towards the scientific method, the second items regarding epistemic authoritarianism, and the third epistemic tolerance. Correlations between the first and second factor are moderate, as well as the second and third, while there is no correlation between the first and third factor (Appendix 3, Table 9).

\subsection{Relationships between Epistemic and Sociopolitical Attitudes and Beliefs about Science}

We have tested our first hypothesis and conducted an exploration of relationships between the main constructs by calculating Pearson correlation coefficients. As performing multiple tests on the same data set increases the chances of obtaining a false positive result, we have tested the correlations against a Bonferroni adjusted alpha level of .008. As Table 2 shows, there is a significant correlation of low intensity between conservatism and epistemic authoritarianism and tolerance in the expected direction and greater than $r=.10$, thus confirming our first hypotheses, $1 \mathrm{a}$ and $1 \mathrm{~b}$. Conservatism is the only variable that has significant correlations with all other constructs, most notably with beliefs about the theory of evolution, as well as a positive low correlation with skepticism towards the scientific method. Skepticism towards the scientific method has a moderate correlation with epistemic authoritarianism. On the other hand, it is not significantly related to epistemic tolerance. Epistemic tolerance 
Table 2 Pearson correlation coefficients of epistemic and sociopolitical attitudes and beliefs about science

\begin{tabular}{|c|c|c|c|c|c|c|}
\hline & 1. & 2. & 3. & 4. & 5. & 6. \\
\hline 1. Epistemic authoritarianism & - & & & & & \\
\hline 2. Epistemic tolerance & $-.38^{* * *}$ & - & & & & \\
\hline 3. Skepticism towards the scientific method & $-.29^{* * *}$ & .06 & - & & & \\
\hline 4. Astrology & -.03 & -.07 & $.26^{* * *}$ & - & & \\
\hline 5. Evolution & .02 & $.08^{*}$ & $-.34^{* * *}$ & $-.28^{* * *}$ & - & \\
\hline 6. Conservatism & $.15^{* * *}$ & $-.19^{* * * *}$ & $.12^{* *}$ & $.19^{* * * *}$ & $-.43^{* * *}$ & - \\
\hline
\end{tabular}

${ }^{*} p<.05 .{ }^{* *} p<.01 .{ }^{* * *} p<.001$

and epistemic authoritarianism, on the other hand, are moderately related. Beliefs about science are not related to epistemic authoritarianism and tolerance, but do have significant relationships with skepticism towards the scientific method.

\subsection{Principal Component Analysis of Epistemic and Sociopolitical Attitudes and Beliefs about Science}

In order to examine the possibility of transforming our set of correlated variables into uncorrelated underlying constructs, we conducted a principal component analysis. The Kaiser-Meyer-Olkin measure of .61 is around .6, the suggested minimum for sampling adequacy (Kaiser and Rice 1974). Bartlett's test of sphericity was statistically significant $\left(\chi^{2}(15)=468.49, p<.001\right)$. Two components with eigenvalues greater than one were extruded, and the model explains $56.74 \%$ of the variance in the data. The first component with an eigenvalue of 1.83 accounts for $30.56 \%$ of the variance in the data, while the second component had an eigenvalue of 1.57 and accounted for further $26.18 \%$ of the variance. Correlations of variables and the components can be found in Table 3 .

Table 3 Results from a principal component analysis of epistemic and sociopolitical attitudes and beliefs about science

\begin{tabular}{|c|c|c|}
\hline \multirow[t]{2}{*}{ Variable } & \multicolumn{2}{|c|}{ Component loading } \\
\hline & 1 & 2 \\
\hline Epistemic authoritarianism & -.08 & -.82 \\
\hline Epistemic tolerance & -.16 & .73 \\
\hline Skepticism towards the scientific method & .61 & .46 \\
\hline Astrology & .61 & .06 \\
\hline Evolution & -.80 & .03 \\
\hline Conservatism & .66 & -.37 \\
\hline
\end{tabular}

Factor loadings above .30 are in bold 
The first component has the highest correlation with beliefs about science, conservatism, as well as skepticism towards the scientific method. This may indicate how sociopolitical attitudes and beliefs about science and the scientific method are intertwined. However, skepticism towards the scientific method and conservatism correlate with the second component as well. This component has the highest correlation with epistemic authoritarianism and epistemic tolerance. This indicates that there is no clear line of demarcation between epistemic attitudes and sociopolitical views and that these components cannot be used in further analyses as a substitute for the main constructs of the study.

Since we assumed that these constructs are theoretically related, we have also conducted a factor analysis. We employed maximum likelihood as an extraction method with promax rotation, in order to allow correlations between factors. The Kaiser-Meyer-Olkin measure of .60 indicates borderline adequate sampling adequacy and Bartlett's test of sphericity was statistically significant $\left(\chi^{2}(15)=197.87, p<.001\right)$. Two factors with eigenvalues greater than one were extruded, with the first factor accounting for $20.1 \%$ of the variance, and the second for $18.4 \%$. The pattern matrix for the 2-factor solution is shown in Table 4.

The structure of these results is complementary to the principal component analysis. Namely, Factor 1 is primarily related to sociopolitical attitudes and beliefs about science, with a moderate loading of skepticism towards the scientific method. Factor 2 is primarily related to epistemic attitudes, as it has the highest loadings with epistemic authoritarianism and tolerance, as well as skepticism. The correlation coefficient between Factor 1 and Factor 2 is $r=-.13$.

\subsection{Epistemic Attitudes and Political Orientation}

In order to test our hypotheses about the interaction of skepticism towards the scientific method with the political orientation of researchers, we have conducted an independent samples $t$-test, as well as a single sample $t$-test. No significant difference was found in skepticism towards the scientific method in relation to the participants' political orientation $(t(366)=-1.82, p>.05)$. Moreover, skepticism towards the scientific method was significantly lower $(M=2.1, S D=0.6)$ than the

Table 4 Results from a factor analysis of epistemic and sociopolitical attitudes and beliefs about science

\begin{tabular}{lcr}
\hline Variable & \multicolumn{2}{l}{ Factor loading } \\
\cline { 2 - 3 } & \multicolumn{1}{l}{1} & 2 \\
\hline Evolution & -.69 & -.08 \\
Conservatism &. $\mathbf{6 3}$ & -.17 \\
Astrology & $\mathbf{. 4 5}$ & .07 \\
Epistemic authoritarianism & .01 & $\mathbf{. 8 5}$ \\
Epistemic tolerance & -.19 & $\mathbf{. 4 4}$ \\
Skepticism towards the scientific method & .28 & $\mathbf{. 4 2}$ \\
\hline
\end{tabular}

Factor loadings above .30 are in bold 
neutral point $(M=3),(t(366)=-28.944, p<.001)$, meaning our hypotheses $2 \mathrm{a}$ and $2 \mathrm{~b}$ were not confirmed.

Further exploration of group differences in political orientation shows that in the case of epistemic authoritarianism $(F(1,475)=5.15, p<.01)$, leftists are significantly more tolerant compared to centrists $(M D=0.2, p<.05)$, while no difference was found compared to rightists $(M D=0.2, p>.05)$. Although the differences are statistically significant, the effect size is $\operatorname{small}^{5}\left(\eta_{\mathrm{p}}{ }^{2}=.02\right)$, and $d=.3$ is below the threshold, meaning this result does not hold scientific significance. The same can be said for epistemic tolerance $(F(1,475)=5.84, p<.01)$, where a significant difference of small effect size $\left(\eta_{\mathrm{p}}{ }^{2}=.02\right)$, and $d=.4$ was found between leftists $(M=4.5 ; S D=0.5)$ and rightists $(M=4.3 ; S D=0.5 ; p<.01)$, with no significant difference between centrist $(M=4.4 ; S D=0.5)$ and leftists or rightists. There was also no differences in beliefs in astrology $(F(1,475)=2.34, p>.05)$, but a moderate effect size $\left(\eta_{\mathrm{p}}{ }^{2}=.10\right)$ with a test power of .99 was found in beliefs about the theory of evolution $(F(1,475)=27.13, p<.001)$, with leftists $(M=4.5 ; S D=0.6)$ scoring higher than centrists $(M=4.1 ; S D=0.7, p<.001)$ and rightists $(M=3.9 ; S D=0.8$, $p<.001)$.

\subsection{Differences in Epistemic Attitudes by Scientific Field and Career Stage}

In order to investigate our hypotheses 3-5, we conducted a between-subjects ANOVA on the participants' scores on epistemic attitudes and beliefs about science with the scientific field and career stage as independent variables. The results show a significant main effect $(F(1,599)=54.67, p<.001)$ of the scientific field with a moderate effect size $\left(\eta_{\mathrm{p}}{ }^{2}=.08\right)$ on epistemic authoritarianism. The mean response for participants in social sciences $(M=2.3 ; S D=0.6)$ was lower than the mean response for participants in the field of natural sciences $(M=2.7 ; S D=0.7)$. The test power was .99 with the effect size of $d=.7$, thus confirming our hypothesis $3 \mathrm{a}$. There was no significant effect of the career stage on epistemic authoritarianism $(F(1,599)=0.02, p>.05)$, meaning our hypothesis $4 \mathrm{a}$ was not confirmed. Similar results were found in the case of epistemic tolerance $\left(F(1,599)=48.83, \eta_{\mathrm{p}}{ }^{2}=.07, p<.001\right)$, as researchers from social sciences $(M=4.6 ; S D=0.4)$ scored significantly higher than the ones from natural sciences $(M=4.3 ; S D=0.6)$. The test power was also .99 with the effect size of $d=.7$, confirming our hypothesis $3 \mathrm{~b}$. No significant interaction was found between the scientific field and career stage in the case of epistemic authoritarianism $(F(1,599)=$ $1.72, p>.05)$, nor epistemic tolerance $(F(1,599)=2.37, p>.05)$.

The analysis conducted on skepticism towards the scientific method shows a significant interaction effect of the scientific field and career stage $(F(1,599)=3.86$, $p<.05, \eta_{\mathrm{p}}^{2}=.01$ ), albeit of small effect size with $d=.5$. Junior researchers in the field of social sciences $(M=2.4 ; S D=0.5)$ are more skeptical than seniors from the same field $(M=2.1 ; S D=0.6)$, while in natural sciences no differences between junior $(M=$

\footnotetext{
${ }^{5}$ Besides the interpretation of the measure $d$, partial eta squared estimates of effect size were interpreted according to benchmarks provided by Cohen (1988). This is the case because, following recommendations made by Lakens (2013), the study design does not include covariates or repeated measures. Additionally, in the literature, our constructs of interest were insufficiently explored. Therefore, there are no established effect sizes for them.
} 
$2.0 ; S D=0.5)$ and senior $(M=2.0 ; S D=0.6)$ researchers were detected, partially confirming hypotheses $3 \mathrm{c}$ and $4 \mathrm{~b} .^{6}$ This interaction is presented in Fig. 2.

When it comes to beliefs in astrology, seniority $(F(1,599)=0.00, p>.05)$ and scientific field $(F(1,599)=0.05, p>.05)$ do not play an important role, meaning hypothesis 5 a was not confirmed. On the other hand, a significant interaction between the participants' scientific field and the career stage was found in the case of beliefs about evolution $\left(F(2,599)=2.77, p<.05, \eta_{\mathrm{p}}{ }^{2}=.01\right)$, with junior researchers in the field of social sciences $(M=4.1 ; S D=0.8)$ holding somewhat weaker beliefs $(d=.5)$ about the theory of evolution than senior researchers from the same field $(M=4.5$; $S D=0.7)$. No difference between junior $(M=4.2 ; S D=0.7)$ and senior $(M=4.3 ; S D=$ 0.8 ) researchers in the field of natural sciences was found (Fig. 3). Thus, hypothesis $5 \mathrm{~b}$ was confirmed for the researchers coming from social sciences.

Finally, a summary of the main findings is presented in Table 5. The table includes a brief description of the hypotheses, as well as the evaluation of the findings with regard to each hypothesis.

\section{Discussion}

As mentioned, the principal aim of our research was to operationalize and empirically test epistemic attitudes, with epistemic tolerance construed as an epistemic virtue, epistemic authoritarianism as an epistemic vice, and skepticism towards the scientific method as a Janus-faced epistemic attitude, rather than virtuous at all times. The first step concerns the confirmation of the quality of the newly proposed scales and the interpretation of the descriptive statistics of all scales presented in the previous section.

When it comes to descriptive statistics, from skewness and kurtosis values, as well as from Kolmogorov-Smirnov tests of normality, we see that none of the relevant variables are normally distributed. This does not necessarily indicate a problem with the used scales but rather reflects upon the underlying nature of the measured phenomena, as well as the characteristics of the scientific community. Our sample of researchers is shown to group around high values in cases of epistemic tolerance and beliefs about the theory of evolution. On the other hand, the participants' scores group around low values in cases of epistemic authoritarianism, skepticism towards the scientific method, and beliefs in astrology. It is important to note that the standardized skewness of conservatism did not deviate from the normal distribution. The high negative value of kurtosis indicates a higher number of cases with extreme values than expected in a normal distribution. Therefore, we were able to ensure the diversity of the sample with regard to conservatism, which cannot be said for the political orientation. Namely, there was a small number of participants who classified themselves as being on the far-right side of the political spectrum. This could be a specific characteristic of the scientific community, though it should be noted that we used convenient sampling methods.

\footnotetext{
${ }^{6}$ These hypotheses are partially confirmed because junior researchers in the field of social sciences are more skeptical towards the scientific method than senior researchers from the same field. However, senior social scientists do not differ from researchers in the field of natural sciences.
} 


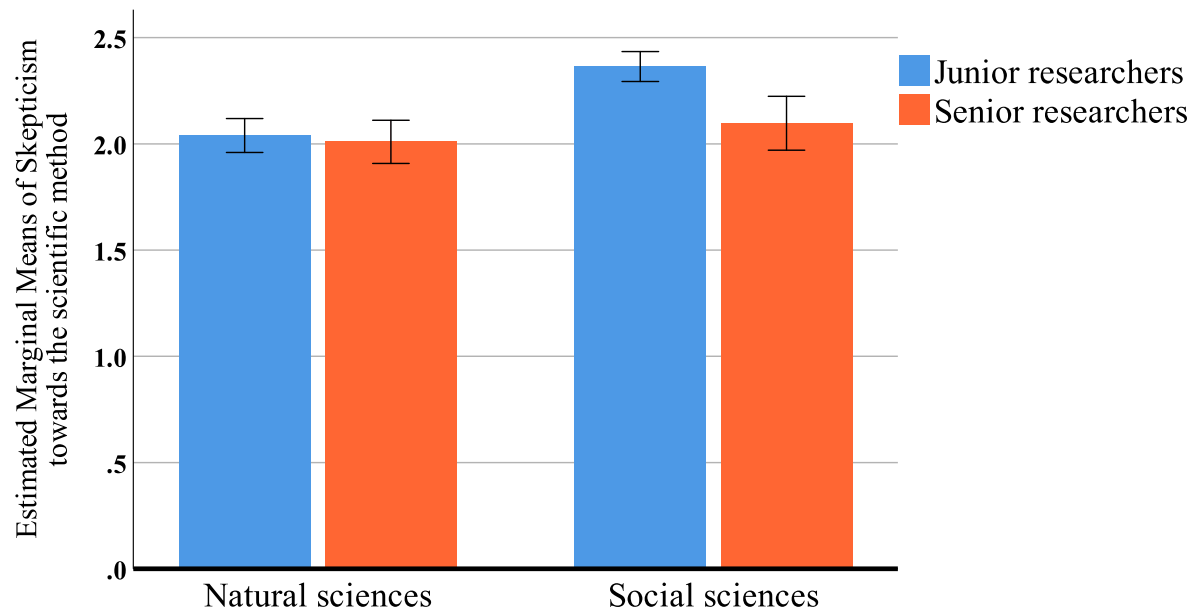

Fig. 2 Interaction between the scientific field and career stage with skepticism towards the scientific method as a dependent variable

As indicated by the internal reliabilities and measures of representativeness, the three proposed scales for epistemic attitudes performed well. The adequateness of the scales is further demonstrated by the results of the confirmatory factor analysis that reproduced the factors of the three scales with the corresponding items. The fact that epistemic authoritarianism and tolerance are moderately correlated, with skepticism being related to epistemic authoritarianism but not tolerance, as well as the results of the principal component analysis, suggest that these constructs cannot be theoretically reduced to one another. ${ }^{7}$

An overview of the main relationships found in the study can be seen in Fig. 4. The relationships between conservatism and epistemic attitudes (epistemic tolerance, epistemic authoritarianism, and skepticism towards the scientific method) are present but weak. This, alongside the fact that our second hypothesis was not confirmed, i.e., that the political orientation does not affect the epistemic attitudes, implies that, contrary to common expectations, political attitudes do not strongly affect professional beliefs and decisions of scientists. This finding goes in the direction that science could be free of political views (cf. Mattes 2019). Moreover, the effect of the scientific field on epistemic attitudes was more relevant than the effect of sociopolitical views. Natural scientists were, on average, more epistemically authoritarian and less epistemically tolerant. This is to be expected given the nature of their field, i.e., the methods used by natural scientists are stricter in comparison to the ones of social scientists. Nonetheless, it is worth noticing that both natural and social scientists are, to a large extent, tolerant, even though social scientists exhibit higher levels of epistemic tolerance.

The career stage also plays a role in the skepticism towards the scientific method, with junior social researchers being more skeptical than seniors in the same field. On the other hand, there are no differences between junior and senior researchers among

\footnotetext{
${ }^{7}$ This interpretation also has a justification in the finding that views on the nature of science may be a system of more or less independent dimensions (Deng et al. 2011).
} 


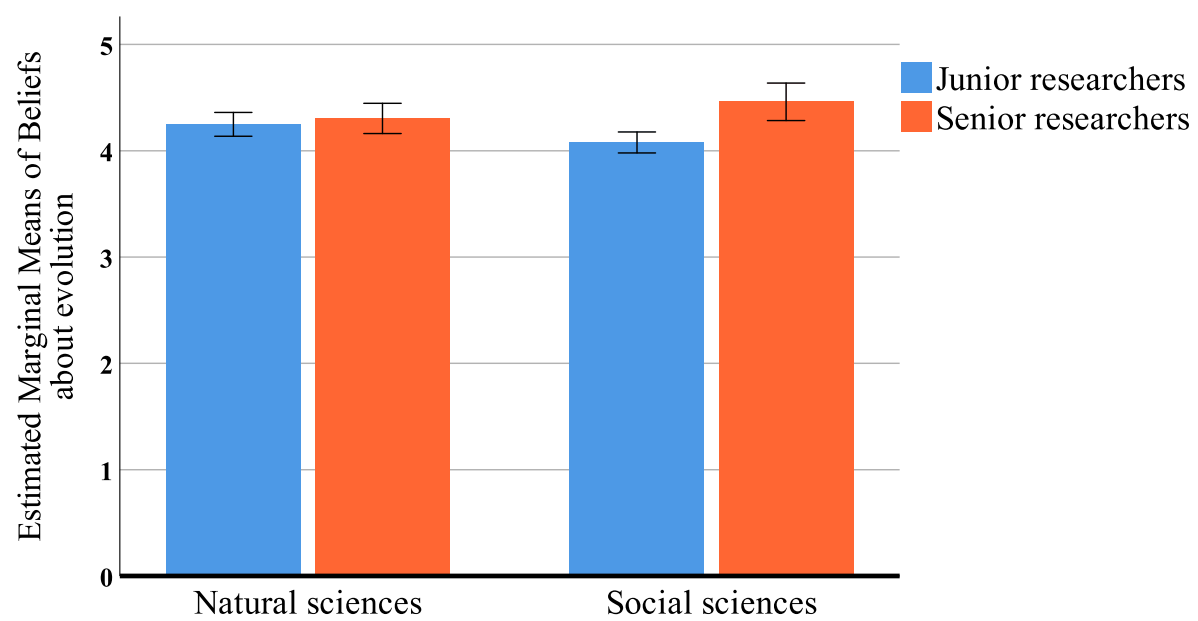

Fig. 3 Interaction between the scientific field and the career stage with beliefs about the theory of evolution as a dependent variable

natural scientists. These results may indicate that with their professional development, researchers' trust in the scientific method increases. On the other hand, it seems that junior researchers in the field of natural sciences do not consider the option of questioning the methods used in their field. This is further supported by the finding that there are no differences in beliefs about the theory of evolution between junior and senior researchers in natural sciences. However, junior researchers in the field of social sciences question the theory of evolution more than seniors. This could indicate that researchers in social sciences develop a greater trust in the scientific method in general during their careers.

We have also investigated the sociopolitical views of scientists. Conservatism has a weak positive correlation with beliefs in astrology. A medium effect was found

Table 5 Summary of the main findings

\begin{tabular}{lll}
\hline Hypothesis ID & Description & Finding \\
\hline $\mathrm{H} 1 \mathrm{a}$ & Correlation between epistemic authoritarianism and conservatism & Confirmed \\
$\mathrm{H} 1 \mathrm{~b}$ & Correlation between epistemic tolerance and conservatism & Confirmed \\
$\mathrm{H} 2 \mathrm{a}$ & Effect of political orientation on skepticism (right-wing) & Not confirmed \\
$\mathrm{H} 2 \mathrm{~b}$ & Effect of political orientation on skepticism (no difference) & Not confirmed \\
$\mathrm{H} 3 \mathrm{a}$ & Effect of scientific field on epistemic authoritarianism & Confirmed \\
$\mathrm{H} 3 \mathrm{~b}$ & Effect of scientific field on epistemic tolerance & Confirmed \\
$\mathrm{H} 3 \mathrm{c}$ & Effect of scientific field on skepticism & Partially confirmed \\
$\mathrm{H} 4 \mathrm{a}$ & Effect of career stage on epistemic authoritarianism & Not confirmed \\
$\mathrm{H} 4 \mathrm{~b}$ & Effect of career stage on epistemic tolerance & Partially confirmed \\
$\mathrm{H} 5 \mathrm{a}$ & Effect of career stage on astrological beliefs & Not confirmed \\
$\mathrm{H} 5 \mathrm{~b}$ & Effect of career stage on beliefs about evolution & Partially confirmed \\
\hline
\end{tabular}




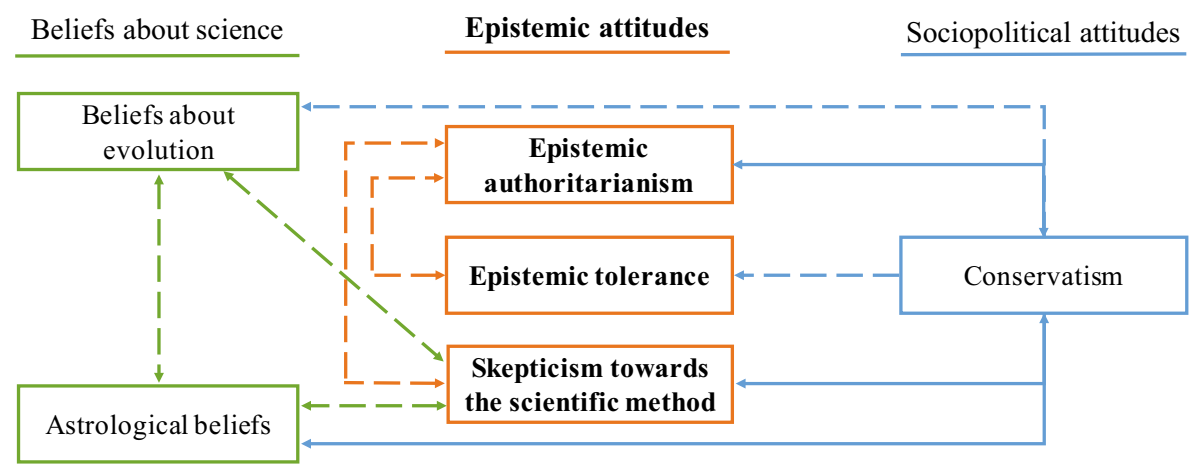

Fig. 4 Overview of the main findings. Note. A full line indicates a positive and a dashed line a negative correlation

between the participants' political orientation and their beliefs about the theory of evolution. These results are in line with the finding that participants who score higher on the conservatism scale are more prone to questioning the theory of evolution (Miller et al. 2006). This is in accordance with our expectations: the results are compatible with the previous findings that different forms of scientific acceptance and rejection are generally grounded in conservatism (Rutjens et al. 2018).

The novelty of our findings stems from the fact that participants in our study are researchers from natural and social sciences. Our study challenges the conclusions of Bayir et al. (2014), who found no differences in natural and social scientists' views on the nature of science. ${ }^{8}$

As previously mentioned, this is an exploratory study, pioneering measures of novel constructs, that are essentially attitudes, some of which are socially desirable. Most notably, our participants showed high levels of epistemic tolerance and low levels of epistemic authoritarianism, as well as little skepticism towards the scientific method. They declared themselves as predominantly liberal and held the theory of evolution in high regard, while the same could not be said about astrology. Therefore, it is important to take these characteristics of the scientific community into account when drawing conclusions and implications from the results. The question remains whether our sample represents the scientific community as a whole and if greater effects would be found if there were more variations within our sample.

\section{Conclusions}

Epistemic tolerance and epistemic authoritarianism play an important role whenever scientists make epistemic decisions about competing theories in their discipline. Epistemically tolerant researchers do not dismiss the work of their peers

\footnotetext{
${ }^{8}$ Some attempts to assess people's views on the nature of science have previously been made with instruments that focus on the student population, as they propose that their views on the nature of science may influence their decisions to pursue further education and involvement with science. An overview of research on this topic can be found in Deng et al. (2011) and Lederman (2007).
} 
with opposing views, while epistemically authoritarian scientists are less willing to revise views that they adopted. On the other hand, skepticism towards the scientific method is connected with the tendency to question and investigate the limits of science. Both epistemic tolerance and epistemic authoritarianism of scientists, as well as their level of skepticism towards the scientific method, were empirically measured for the first time. We proposed three measuring scales. The conducted analyses showed that all of the scales capture independent phenomena and that they are statistically reliable. Additionally, we compared the epistemic attitudes with the sociopolitical views of our survey participants in order to examine whether their epistemic attitudes are in any way "sullied" by their political orientation and level of conservatism.

Our results represent a positive finding regarding the scientific community: scientists, at least on a declarative level, see themselves as epistemically tolerant towards opposing theories and approaches, and not epistemically authoritarian. These values influence their epistemic decisions, such as equal consideration of rivaling theories in their field. On the other hand, the results revealed that the epistemic attitudes of scientists are, to a certain degree, dependent on their discipline and the level of their experience. As expected, given the irregular patterns governing their field of expertise, social scientists are to some extent more epistemically tolerant. Moreover, junior researchers in social sciences tend to relativize the scientific method more than their experienced colleagues. We attribute this finding to the fact that they are new to science and most likely did not yet become advocates for any specific approach. When it comes to endorsing pseudoscience, scientists dismissed believing in astrology almost unanimously, regardless of their political orientation, field of expertise, or career stage. Interestingly, junior researchers in social sciences also tend to believe less in evolutionary theory than the senior researchers, while such a difference was not found between junior and senior researchers in natural sciences. Finally, as for the impact of sociopolitical views on the corpus of epistemic attitudes, we pointed out that the tested epistemic values are not influenced by political orientation and are only weakly correlated with conservatism. Rather, the specific scientific field directs one's level of epistemic tolerance. Hence, based on our findings, the influence that political attitudes have on the epistemic decisions of scientists is marginal.

Following Bruder et al. (2013) who showed that their Conspiracy Mentality Questionnaire could be used for exploring the differences in beliefs in conspiracy theories across European, North American and Middle Eastern population, it would be interesting, for further research, to conduct a cross-national study that would investigate the views of researchers coming from different sociopolitical backgrounds and academic cultures. It would also be interesting to further investigate the interplay between the proposed scales for measuring epistemic attitudes and other similar constructs such as intellectual humility (e.g., Alfano et al. 2017.) or open-mindedness (e.g., Fujita et al. 2007), as well as their non-epistemic counterparts, i.e., political intolerance and authoritarianism (e.g., Crawford \& Pilanski 2014), and even character traits such as openness and agreeableness (e.g., Kajonius and Dåderman 2014). Finally, it would be relevant to adapt the proposed scales for measuring epistemic attitudes in the general population. 
Acknowledgments We would like to thank Kaja Damnjanović, Dušica Filipović Đurđević, and Jovan Ivanović for reading and commenting upon the methodological aspects of our research, and Jan Sprenger for his suggestions that lead to a significant improvement of the theoretical parts of our paper. We would also like to thank Monika Milosavljević and other participants in the discussion after our research was presented at the Laboratory for Experimental Psychology, Belgrade, Serbia, as well as the participants in the discussion after the presentation at Science \& More Seminar in Turin, Italy. We also appreciate the suggestions and constructive criticism of the anonymous reviewers. Finally, we are grateful to the researchers who found the time to participate in our survey and, thus, made this empirical study possible.

Funding Information Open Access funding provided by Projekt DEAL.

\section{Appendix 1}

Table 6 Distribution of participants' scientific field

\begin{tabular}{|c|c|c|c|c|}
\hline Scientific field & Scientific discipline & Junior researchers & Senior researchers & Total \\
\hline \multirow[t]{9}{*}{ Social sciences } & Anthropology & 4 & 8 & 12 \\
\hline & Archeology & 9 & 10 & 19 \\
\hline & Philology & 7 & 8 & 15 \\
\hline & Philosophy & 32 & 4 & 36 \\
\hline & Humanities (other) & 12 & 2 & 14 \\
\hline & History & 37 & 8 & 45 \\
\hline & Psychology & 91 & 15 & 106 \\
\hline & Sociology & 32 & 17 & 49 \\
\hline & Social sciences (other) & 11 & 2 & 13 \\
\hline \multirow[t]{9}{*}{ Natural Sciences } & Biology & 50 & 50 & 100 \\
\hline & Chemistry & 8 & 10 & 18 \\
\hline & Mathematics & 5 & 7 & 12 \\
\hline & Physics & 21 & 30 & 51 \\
\hline & Natural sciences (other) & 5 & 2 & 7 \\
\hline & Electrical engineering & 56 & 3 & 59 \\
\hline & Computer sciences & 24 & 6 & 30 \\
\hline & Medicine & 13 & 4 & 17 \\
\hline & Total & 417 & 186 & 603 \\
\hline
\end{tabular}

Table 7 Distribution of participants' career stage

\begin{tabular}{llrr}
\hline Career stage & Education level & Frequency & Percent \\
\hline Junior researchers & Undergraduate students & 262 & 42.6 \\
& Bachelor's or Master's degree & 99 & 16.1 \\
& Doctoral students & 103 & 16.7 \\
Senior researchers & Doctorate degree & 151 & 24.6 \\
& Total & 615 & 100.0 \\
\hline
\end{tabular}




\section{Appendix 2}

\section{Instructions}

Participants read the following text and gave their informed consent:

\section{Research on attitudes regarding the scientific method}

We invite You to take part in an investigation of epistemic attitudes regarding the scientific method that is conducted by a group of researchers from [institution omitted for the blind review].

Participation in this survey is anonymous and classified, so we encourage You to be honest and answer all questions. There are no right or wrong answers. The results of this research will be used solely for scientific purposes. Participation in this survey is voluntary and You may withdraw at any time.

Filling out this survey will take approximately $10 \mathrm{~min}$.

Thank you for your cooperation!

In case you have any questions or concerns, You can contact us via email [email address omitted for the blind review].

\section{Informed Consent}

This survey is anonymous, i.e., it does not collect personal information about the participant, as well as confidential, i.e., no one other than the researcher will have access to the data that will be used for scientific purposes only.

I confirm that my participation in this survey is voluntary and that I understand and accept the conditions of anonymity and confidentiality. (yes/no)".

\section{Survey Items}

Note that the survey was conducted in the Serbian language. However, for the purpose of this paper, we present the English translations of the items. All items within one section were appearing in random order.

\section{Section I}

Participants were asked to read each statement carefully and mark one answer ranging from 1 to 5 (1- I completely disagree, 5 - I completely agree) based on their level of agreement.

\section{Epistemic tolerance scale}

It was explained that the statements refer to the specific field of the participants' expertise.

1. It is important to compare different sources in my scientific field.

2. The opinions of the researchers I disagree with should be taken into consideration.

3. Theories in my scientific field need to be revised from time to time. 
4. Opinions that go against the prevailing theory in my scientific field should also be considered.

5. Researchers in my field often make mistakes.

6. Even the papers of the researchers I disagree with are scientifically valuable.

7. There is a chance that the researchers with whom I disagree are, in fact, right.

\section{Epistemic authoritarianism scale}

It was indicated that the items refer to the specific field of the participants' expertise.

1. Some of the results within my scientific field are conclusively proven and should not be questioned.

2. One should rely only on sources whose scientific value has already been established.

3. The method that we apply in my scientific field is rigorous and the only correct one.

4. The method that is currently dominant in my field is the only one that should be used.

5. It is pointless to have a debate with researchers who reject the dominant paradigm in my scientific field.

6. The problems within my scientific field can be fully explained by widely accepted theories in the field.

7. The academic authorities in my field are right.

\section{Skepticism about the scientific method scale}

It was explained that the statements refer to science in general. The items appeared in random order.

\section{Scientists' subjectivity}

1. In their work scientists can never distance themselves enough from their own views.

2. Every proof is only someone's opinion.

3. What scientists publish is more a reflection of their beliefs than the objective truth.

4. Scientists cannot avoid the influence of their prejudices.

\section{Stochastic progress of science}

1. Only by chance does science produce applicable results.

2. Progress in science is achieved solely by mere chance.

3. The major scientific discoveries happen at random. 
Intelligibility of the objective truth

1. The scientific method cannot be objective.

2. Even the laws of mathematics will be revised in the future.

3. The scientific method cannot reveal the regularities found in nature and society.

4. Not even mathematics can reveal objective truth.

5. Science will never be able to adequately describe reality.

\section{Section II}

Adapted Social and Economic Conservatism Scale (from Everett 2013)

Participants were asked to rank how strongly they feel about the following notions on a scale from 10 to 100 .

1. Abortion.

2. Welfare benefits (reverse scoring).

3. Tax (reverse scoring).

4. Limited government.

5. Military and national security.

6. Religion.

7. Traditional marriage.

8. Traditional values.

9. Fiscal responsibility.

10. Business.

11. The family unit.

12. Patriotism.

\section{Self-report measure of political orientation}

The participants were asked to position themselves on the political spectrum using a 7-point scale ranging from far left until far right.

1. Far left.

2. Left.

3. Moderately left.

4. Center.

5. Moderately right.

6. Right.

7. Far right.

8. Prefer not to declare. 


\section{Appendix 3}

Table 8 Pattern matrix - confirmatory factor analysis (Promax rotation)

Items Factor

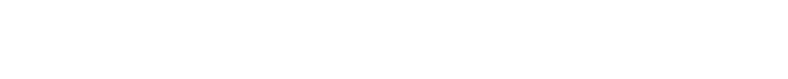

$2 \quad 3$

Some of the results within my scientific field are conclusively proven and should not be questioned.

One should rely only on sources whose scientific value has already been established.

The method that we apply in my scientific field is rigorous and the only correct one.

The method that is currently dominant in my field is the only one that should be used.

It is pointless to have a debate with researchers who reject the dominant paradigm in my scientific field.

The problems within my scientific field can be fully explained by widely accepted theories in the field.

The academic authorities in my field are right.

It is important to compare different sources in my scientific field.

The opinions of the researchers I disagree with should be taken into consideration.

Theories in my scientific field need to be revised from time to time.

Opinions that go against the prevailing theory in my scientific field should also be considered.

Researchers in my field often make mistakes.

Even the papers of the researchers I disagree with are scientifically valuable.

There is a chance that the researchers with whom I disagree are, in fact, right.

In their work scientists can never distance themselves enough from their own views.

Every proof is only someone's opinion.

What scientists publish is more a reflection of their beliefs than the objective truth.

Scientists cannot avoid the influence of their prejudices.

Only by chance does science produce applicable results.

Progress in science is achieved solely by mere chance.

The major scientific discoveries happen at random.

The scientific method cannot be objective.

Even the laws of mathematics will be revised in the future.

The scientific method cannot reveal the regularities found in nature and society.

Science will never be able to adequately describe reality. 
Table 9 Intercorrelations for factors - epistemic attitudes

\begin{tabular}{lccc}
\hline & 1 & 2 & 3 \\
\hline F1 (Skepticism toward the scientific method) & - & .39 & .06 \\
F2 (Epistemic authoritarianism) & .39 & - & .50 \\
F3 (Epistemic tolerance) & .06 & .50 & - \\
\hline
\end{tabular}

Open Access This article is licensed under a Creative Commons Attribution 4.0 International License, which permits use, sharing, adaptation, distribution and reproduction in any medium or format, as long as you give appropriate credit to the original author(s) and the source, provide a link to the Creative Commons licence, and indicate if changes were made. The images or other third party material in this article are included in the article's Creative Commons licence, unless indicated otherwise in a credit line to the material. If material is not included in the article's Creative Commons licence and your intended use is not permitted by statutory regulation or exceeds the permitted use, you will need to obtain permission directly from the copyright holder. To view a copy of this licence, visit http://creativecommons.org/licenses/by/4.0/.

\section{References}

Alfano, M., K. Iurino, P. Stey, B. Robinson, M. Christen, F. Yu, and D. Lapsley. 2017. Development and validation of a multi-dimensional measure of intellectual humility. PLoS One 12 (8): e0182950.

Anvari, F., and D. Lakens. 2019. Using anchor-based methods to determine the smallest effect size of interest. PsyArXiv. https://doi.org/10.31234/osf.io/syp5a.

Battaly, H. 2014. Varieties of epistemic vice. In The ethics of belief, ed. J. Matheson and R. Vitz, 51-77. Oxford: Oxford University Press.

Bayir, E., Y. Cakici, and O. Ertas. 2014. Exploring natural and social scientists' views of nature of science. International Journal of Science Education 36 (8): 1286-1312.

Bruder, M., P. Haffke, N. Neave, N. Nouripanah, and R. Imhoff. 2013. Measuring individual differences in generic beliefs in conspiracy theories across cultures: Conspiracy mentality questionnaire. Frontiers in Psychology 4: 225.

Brysbaert, M. 2019. How many participants do we have to include in properly powered experiments? A tutorial of power analysis with reference tables. Journal of Cognition 2(1). http://doi.org/10.5334/joc.72.

Chang, H. 2012. Is water H2O? Evidence, Pluralism and Realism. Springer.

Crawford, J.T. and J.M. Pilanski. 2014. Political intolerance, right and left. Political Psychology 35 (6), $841-$ 851.

Cohen, J. 1988. Statistical power analysis for the behavioral sciences. New York: Routledge Academic.

Colombo, M., L. Bucher, and Y. Inbar. 2016. Explanatory judgment, moral offense and value-free science. Review of Philosophy and Psychology 7: 743-763.

Deng, F., D.T. Chen, C.C. Tsai, and C.S. Chai. 2011. Students' views of the nature of science: A critical review of research. Science Education 95 (6): 961-999.

Douglas, H. 2000. Inductive risk and values in science. Philosophy of Science 67 (4): 559-579.

Douglas, H. 2009. Science, policy, and the value-free ideal. Pittsburgh: University of Pittsburgh Press.

Dunlap, R.E., and A.M. McCright. 2008. A widening gap: Republican and democratic views on climate change. Environment: Science and Policy for Sustainable Development 50 (5): 26-35.

Elliott, K.C. 2011. Direct and indirect roles for values in science. Philosophy of Science 78 (2): 303-324.

Estlund, David. 1992. Making truth safe for democracy. In The idea of democracy, ed. D. Copp et al., 71-100. Cambridge: Cambridge University Press.

Everett, J.A. 2013. The 12 item social and economic conservatism scale (SECS). PLoS One 8 (12): e82131.

Feyerabend, P. 1975/1993. Against method: An outline of an anarchistic theory of knowledge. New York: Verso Books.

Frame, J.D., and M.P. Carpenter. 1979. International research collaboration. Social Studies of Science 9: 481-497.

Fujita, K., M.G. Peter, and G. Oettingen. 2007. Mindsets and pre-conscious open-mindedness to incidental information. Journal of Experimental Social Psychology 43 (1): 48-61. 
Hamilton, L.C., J. Hartter, and K. Saito. 2015. Trust in scientists on climate change and vaccines. SAGE Open 5 (3): 215824401560275 . https://doi.org/10.1177/2158244015602752.

Ioannidis, J.P.A. 2005. Why most published research findings are false. PLoS Medicine 2 (8): e124.

Jaffe, K. 2014. Social and natural sciences differ in their research strategies, adapted to work for different knowledge landscapes. PLoS One 9 (11): e113901.

Johnson, R.L., and E.E. Peeples. 1987. The role of scientific understanding in college: Student acceptance of evolution. The American Biology Teacher 49: 93-98.

Jost, J.T., J. Glaser, A.W. Kruglanski, and F.J. Sulloway. 2003. Political conservatism as motivated social cognition. Psychological Bulletin 129 (3): 339-375.

Kaiser, H.F., and J. Rice. 1974. Little jiffy, mark IV. Educational and Psychological Measurement 34 (1): 111-117.

Kajonius, P.J., and A.M. Dåderman. 2014. Exploring the relationship between honesty-humility, the big five, and liberal values in Swedish students. Europe's Journal of Psychology 10 (1): 104-117.

Kitcher, P. 1990. The division of cognitive labor. Journal of Philosophy 87 (1): 5-22.

Kitcher, P. 1993. The advancement of science. New York: Oxford University Press.

Krumrei-Mancuso, E.J. and B. Newman. 2020. Intellectual humility in the sociopolitical domain. Self and Identity. https://doi.org/10.1080/15298868.2020.1714711.

Kuhn, T. 1962/1970. The structure of scientific revolutions. Chicago: The University of Chicago Press.

Kuhn, T.S. 1977/2000. Rationality and theory choice. In The road since 'structure', ed. J. Conant and J. Haugeland, 208-215. Chicago: The University of Chicago Press.

Kuhn, T. 1977a. The essential tension: Tradition and innovation in scientific research. In The essential tension: Selected studies in scientific tradition and change, ed. T. Kuhn, 225-239. Chicago: University of Chicago Press.

Kuhn, T. 1977b. Logic of discovery or psychology of research. In The essential tension: Selected studies in scientific tradition and change, ed. T. Kuhn, 266-292. Chicago: University of Chicago Press.

Kuhn, T. 1977c. Objectivity, value judgment, and theory choice. In The essential tension: Selected studies in scientific tradition and change, ed. T. Kuhn, 320-339. Chicago: University of Chicago Press.

Lakens, D. 2013. Calculating and reporting effect sizes to facilitate cumulative science: A practical primer for t-tests and ANOVAs. Frontiers in Psychology 4: 863.

Lederman, N.G. 2007. Nature of science: Past, present, and future. In Handbook of research on science education, ed. S.K. Abell and N.G. Lederman, 831-881. Routledge.

Longino, H. 2002. The fate of knowledge. Princeton: Princeton University Press.

Luukkonen, T. 1992. Understanding patterns of international scientific collaboration. Science, Technology, Human Values 17: 101-126.

Martin, E. 2019. The battle is on: Lakatos, Feyerabend, and the student protests. European Journal of Philosophy of Science, 9. https://doi.org/10.1007/s13194-019-0251-y.

Mattes, J. 2019. Reports of the death of value-free science are greatly exaggerated. Review of Philosophy and Psychology 10: 689-699. https://doi.org/10.1007/s13164-018-0426-z.

Miller, J.D., Scott, E.C. and S. Okamoto. 2006. Public acceptance of evolution. Science 313 (5788): 765-766.

Nunnally, J.C., and I.H. Bernstein. 1994. Psychometric theory. 3rd ed. Mcgraw-Hill: New York.

Open Science Collaboration. 2015. Estimating the reproducibility of psychological science. Science 349 (6251): aac4716-aac4716.

Parish, A.J., K.W. Boyack, and J.P.A. Ioannidis. 2018. Dynamics of co-authorship and productivity across different fields of scientific research. PLoS One 13 (1): e0189742.

Persson, O., W. Flanzel, and R. Danell. 2004. Inflationary bibliometric values: The role of scientific collaboration and the need for relative indicators in evaluative studies. Scientometrics 60: 421-432.

Popper, K. 1945a. The open society and its enemies: The spell of Plato. London: Routledge.

Popper, K. 1945b. The open society and its enemies: The high tide of prophecy: Hegel, Marx, and the aftermath. London: Routledge.

Popper, K. 1957. The poverty of historicism. Boston: The Beacon Press.

Popper, K. 1994. The myth of the framework: In Defence of science and rationality. London \& New York: Routledge.

Randall, T.M., and M. Desrosiers. 1980. Measurement of supernatural belief: Sex differences and locus of control. Journal of Personality Assessment: 493-498.

Rutjens, B.T., R.M. Sutton, and R. van der Lee. 2018. Not all skepticism is equal: Exploring the ideological antecedents of science acceptance and rejection. Personality and Social Psychology Bulletin 44: 384-405.

Sedlmeier, P., and G. Gigerenzer. 1989. Do studies of statistical power have an effect on the power of studies? Psychological Bulletin 105 (2): 309-316. 
Straßer, C., D. Šešelja, and J.W. Wieland. 2015. Withstanding tensions: Scientific disagreement and epistemic tolerance. In Heuristic reasoning. Studies in Applied Philosophy, Epistemology and Rational Ethics, ed. E. Ippoliti, vol. 16, 113-146. Cham: Springer.

Strevens, M. 2003. The role of the priority rule in science. Journal of Philosophy 100 (2): 55-79.

Sullivan, G.M. and R. Feinn. 2012. Using effect size — or why the P value is not enough. Journal of graduate medical education 4(3): 279-282.

Zollman, K.J. 2007. The communication structure of epistemic communities. Philosophy of Science 74 (5): 574-587.

Zollman, K.J. 2010. The epistemic benefit of transient diversity. Erkenntnis 72 (1): 17-35.

Publisher's Note Springer Nature remains neutral with regard to jurisdictional claims in published maps and institutional affiliations.1 